\title{
Hot Tearing Sensitivity of Al-Mg-Si Alloys Evaluated by X-Ray Microtomography After Constrained Solidification at High Cooling Rate
}

\author{
E. Giraud, M. Suéry, J. Adrien, E. Maire, and M. Coret
}

\section{Introduction}

It is well-known that some aluminum alloys are sensitive to hot cracking such as $\mathrm{Al}-\mathrm{Cu}$ or Al-Mg-Si alloys [1-3]. During welding processes, cracks can form in the molten zone thus limiting their applications. To reduce this phenomenon, many solutions are available among them changing the alloy composition by using a filler wire $[1,2]$. In the case of Al-Mg-Si alloys, it is common to use a filler alloy from the $\mathrm{Al}-\mathrm{Si}$ or Al-Mg series. However, the composition of the molten zone, which is required to reduce hot tearing susceptibility, is still not precisely known since it depends on the base alloy, the alloy used for the filler wire and the welding conditions. Consequently, to determine the appropriate composition, it is necessary to investigate the behavior of various mixtures of the base and filler alloys under conditions close to those encountered during welding.

Many techniques have been developed to assess hot tearing susceptibility [3]. The ring mould testing is frequently used to evaluate the hot tearing tendency of aluminum alloys $[3,4]$. The mould consists of a ring and a core. The liquid is poured into the space between the two parts of the mould. During solidification, the core hinders solidification shrinkage and thermal contraction of the solidifying mixture therefore leading to hot tearing. The hot tearing susceptibility is then related to the length of the main crack. The major limitation of this technique is that the solidification conditions are usually different from those encountered during welding. A more appropriate technique is the Varestraint test [5]. It consists in applying a strain of known magnitude to a weld coupon during the welding process. The deformation is made by bending the weld coupon over a mandrel and forcing it to conform to the radius of the mandrel. The crack susceptibility is then determined by measuring the total length of cracks obtained for a particular applied strain. However, another type of tests allows reaching the solidification conditions encountered during welding without performing joints, namely tensile tests during solidification [3, 6-8]. In

\section{E. Giraud $(\otimes)$}

SIMaP, Universités de Grenoble, CNRS UMR5266, Saint Martin d'Hères Cedex, France e-mail: eliane.giraud@ simap-grenoble-inp.fr 
this type of test, a sample is mounted on a tensile testing machine and is locally melted. A tensile strain is then applied during solidification of the molten zone by either moving or keeping fixed the crosshead of the tensile machine. In this latter case named constrained solidification, the tensile strain generated in the molten zone is only due to thermal contraction and solidification shrinkage in the specimen. In both cases, the sample is connected to a load cell which allows recording the stress resulting from the deformation of the solid as a function of temperature.

The aim of this paper is to report the results of constrained solidification experiments carried out both on a 6061 alloy and on alloys with various Si or Mg contents. In order to reproduce conditions close to welding, the experiments were carried out at high cooling rate starting from the liquid. After the experiments, the zone of the specimen which was initially liquid has been observed by X-ray microtomography in order to detect possible cracks. The hot cracking sensitivity of the various alloys was then determined based on the volume fraction and the number of open cracks in the molten zone.

\section{Experimental Procedure}

\section{Materials}

The 6061 alloy was used as the base metal and 4043, 4047 and 5356 alloys were used to change the composition of the base metal since they are employed as filler alloys during welding. The AA6061 alloy was supplied as rolled plates, $50 \mathrm{~mm}$ in thickness and in the T6 condition (solution heat treated and then artificially aged). The AA4043 (Al-5Si) and AA5356 (Al-5 Mg) alloys were supplied as wire of $1.6 \mathrm{~mm}$ diameter. The AA4047 (Al-12Si) was supplied as wire of $1.4 \mathrm{~mm}$ diameter. The compositions of the various alloys are given in Table 1.

Alloys with various compositions were prepared by mixing various amounts of the base metal and the filler wire. The weight percent of $\mathrm{Mg}$ or $\mathrm{Si}$ in the mixture is then given by:

$$
[X]_{\text {Mixture }}=\frac{m_{B A}}{M} \cdot[X]_{B A}+\frac{m_{F A}}{M} \cdot[X]_{F A}
$$

Table 1 Chemical composition (wt $\%$ ) of the various alloys

\begin{tabular}{llllllll}
\hline & $\mathrm{Si}$ & $\mathrm{Mg}$ & $\mathrm{Fe}$ & $\mathrm{Cr}$ & $\mathrm{Mn}$ & $\mathrm{Cu}$ & $\mathrm{Al}$ \\
\hline 6061 & 0.61 & 0.93 & 0.26 & 0.20 & 0.12 & 0.28 & $\mathrm{Bal}$. \\
4043 & 4.7 & 0.004 & 0.3 & - & 0.01 & 0.01 & $\mathrm{Bal}$. \\
4047 & 11.25 & 0.001 & 0.20 & - & 0.001 & 0.0009 & $\mathrm{Bal}$. \\
5356 & 0.03 & 5.06 & 0.02 & 0.12 & 0.14 & - & $\mathrm{Bal}$. \\
\hline
\end{tabular}




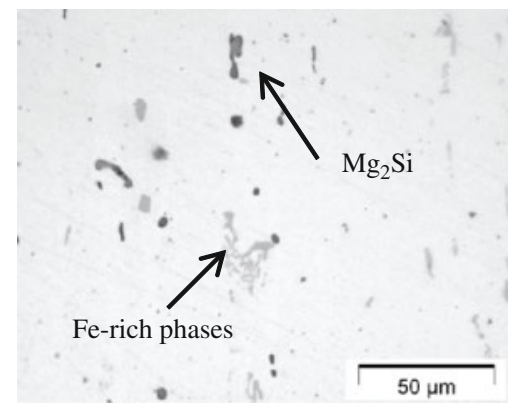

(a)

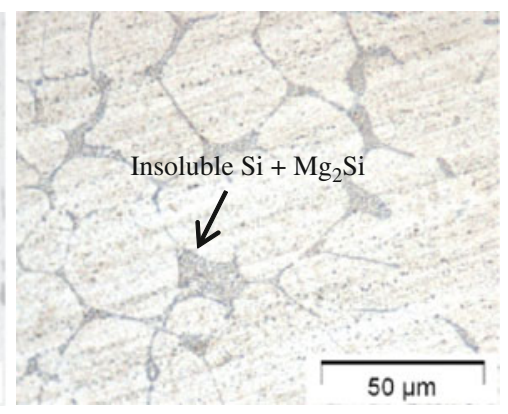

(b)

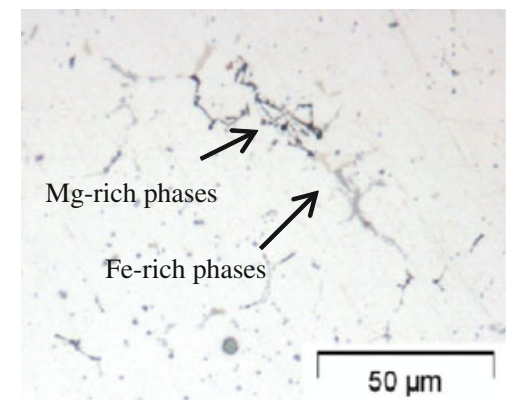

(c)

Fig. 1 Microstructure of 6061 (a), alloy containing 3 wt $\%$ of Si (b), alloy containing 3 wt $\%$ of $\mathrm{Mg}(\mathbf{c})$ - No etching

with: $[\mathrm{X}]$ the weight percent of the considered element $(\mathrm{Si}$ or $\mathrm{Mg})$ in the mixture, in the base alloy (BA) and in the filler alloy (FA); $\mathrm{m}$ is the mass of the base or filler alloy; $\mathrm{M}$ the total mass.

Nine alloys were studied: the 6061 alloy (as reference); alloys containing 1, 2 and $3 \mathrm{wt} \%$ of Si (obtained by mixing 6061 and 4043); alloys containing 4 and $5 \mathrm{wt} \%$ of $\mathrm{Si}$ (obtained by mixing 6061 and 4047); and alloys containing 2, 3 and $4 \mathrm{wt} \%$ of $\mathrm{Mg}$. Figure 1 shows typical microstructures of the alloys. In the base metal, typical $\mathrm{Mg}_{2} \mathrm{Si}$ (dark) and iron-rich phases (light) are present. When the Si content increases, Si phases appear besides those encountered in the base alloy. No microstructural differences are found between mixtures obtained by using the 4043 or the 4047 alloy. When increasing the $\mathrm{Mg}$ content, iron-rich phases (light) and magnesium-rich phases (dark) are present.

\section{Mechanical Tests Under Constrained Solidification Conditions}

Figure 2 shows the experimental device used for the mechanical tests. An Adamel DY34 machine equipped with a $10 \mathrm{kN}$ load cell was employed. The samples were cylinders of $9.5 \mathrm{~mm}$ diameter and $120 \mathrm{~mm}$ length. 
Fig. 2 Sketch of the experimental device used for the constrained solidification

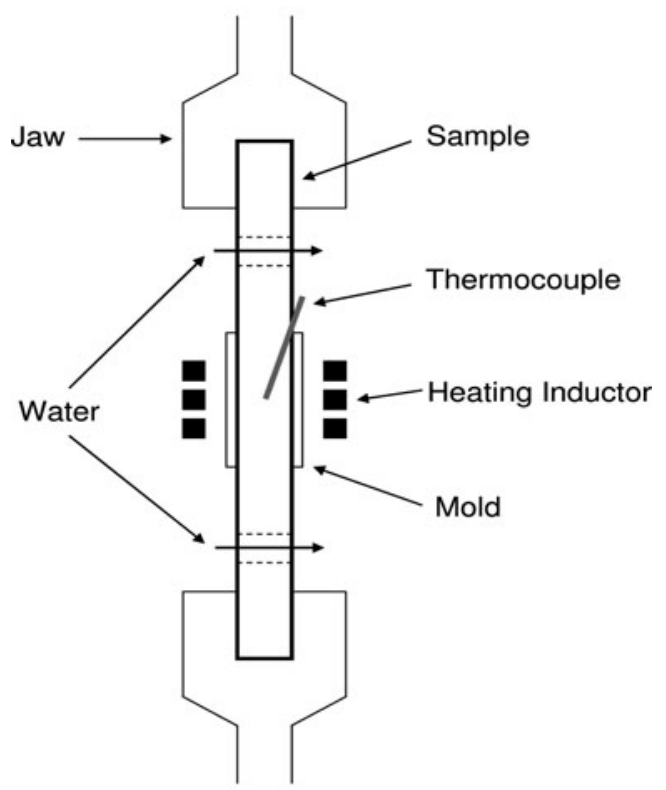

The central part of the sample was heated by induction at $2 \mathrm{~K} / \mathrm{s}$ until the liquid state. The temperature was measured by a K-type thermocouple of $0.5 \mathrm{~mm}$ diameter located in the central part of the sample. The deformations due to the heating were accommodated by moving the crosshead of the machine. An alumina crucible was placed around the heated zone to maintain the liquid in the center of the sample when very high liquid fractions are reached. Once the central part was liquid, the sample was cooled by keeping the crosshead fixed. Thus, the accommodation of thermal contraction and solidification shrinkage was prevented leading to constrained solidification. The cooling rate was about $80 \mathrm{~K} / \mathrm{s}$ thanks to a water flow on both sides of the molten zone. The evolution of the load generated by constrained solidification was recorded in real time as a function of temperature. The temperature was linked to solid fraction by using the Alcan ProPhase software (based on the diffusion model of Sigli et al. [9]). Table 2 gives the evolution of solid fraction with temperature for the various alloys.

\section{X-Ray Microtomography Procedure}

Specimens of $2 \mathrm{~mm}$ diameter were machined from the zone of each sample which has been completely melted and solidified under constrained conditions. The specimens were then imaged by X-Ray microtomography carried out in INSA Lyon. During the rotation of the specimen over $180^{\circ}, 1400$ transmission images were recorded. The pixel size was set to $2 \mu \mathrm{m}$. After data acquisition, three-dimensional (3-D) images of the specimen were reconstructed using standard reconstruction tools. 
Table 2 Temperature (K) and corresponding solid fraction (Fs) for the various alloys investigated

\begin{tabular}{lccccccc}
\hline Alloy/Fs & 0.6 & 0.80 & 0.90 & 0.95 & 0.97 & 0.99 & 1 \\
\hline 6061 & 910 & 894 & 873 & 861 & 853 & 806 & 779 \\
$1 \% \mathrm{Si}$ & 906 & 888 & 863 & 838 & 821 & 807 & 779 \\
$2 \% \mathrm{Si}$ & 895 & 869 & 827 & 824 & 822 & 810 & 779 \\
$3 \% \mathrm{Si}$ & 883 & 870 & 831 & 824 & 822 & 811 & 749 \\
$4 \% \mathrm{Si}$ & 868 & 836 & 826 & 825 & 823 & 813 & 779 \\
$5 \% \mathrm{Si}$ & 853 & 837 & 829 & 825 & 824 & 816 & 779 \\
$2 \% \mathrm{Mg}$ & 901 & 880 & 869 & 864 & 845 & 727 & 692 \\
$3 \% \mathrm{Mg}$ & 893 & 868 & 853 & 809 & 724 & 692 & 692 \\
$4 \% \mathrm{Mg}$ & 884 & 857 & 821 & 727 & 707 & 699 & 692 \\
\hline
\end{tabular}

The hot tearing tendency of each alloy was evaluated by determining the quantity of cracks present in the 3-D images. This quantity was evaluated through two parameters: the volume fraction and the number of open cracks. These data were obtained by digital processing of the 3-D images. A conventional threshold (black/white) was used to separate the cracks and the solid, a crack corresponding to black pixels connected with each other. It is then easy to determine the number of cracks per unit volume. In the same way, the volume percent of open cracks is equal to the sum of the volume of each crack divided by the volume of the analyzed zone. The volume of each crack is deduced from the corresponding number of pixels, the pixel size being known.

\section{Experimental Results}

\section{Mechanical Tests Under Constrained Solidification Conditions}

Figure 3 shows the variation of stress as a function of solid fraction for the various alloys. The influence of the Si content is shown in Fig. 3a and the influence of the $\mathrm{Mg}$ content in Fig. 3b. The behavior of the alloys containing only 3 and $5 \mathrm{wt} \% \mathrm{Si}$ and 3 and $4 \mathrm{wt} \% \mathrm{Mg}$ are shown for a better clarity of the figures. The other alloys exhibit the same trend as that shown in Fig. 3. Stress is obtained by dividing the measured load by the cross section of the sample.

For the 6061 alloy, stress starts increasing for a solid fraction of 0.6 and continues increasing up to a solid fraction of 1 . However, at a solid fraction of 0.97 , the curve exhibits a sharp transition. Below 0.97, stress increases slowly, while, at higher solid fractions, stress increases much more rapidly.

Whatever the Si or Mg content, the stress-solid fraction curve exhibits the same shape with the stress starting to increase at a solid fraction of 0.6 and a transition in its slope at a solid fraction which depends on the Mg content only. Indeed the transition is shifted toward lower solid fractions when the $\mathrm{Mg}$ content increases. 
Fig. 3 Evolution of the measured stress as a function of the solid fraction during the solidification of alloys with different Si contents (a) and with different $\mathrm{Mg}$ contents (b)

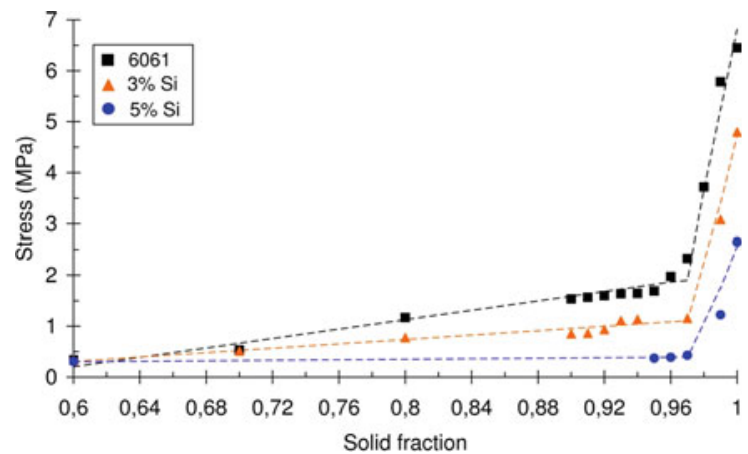

(a)

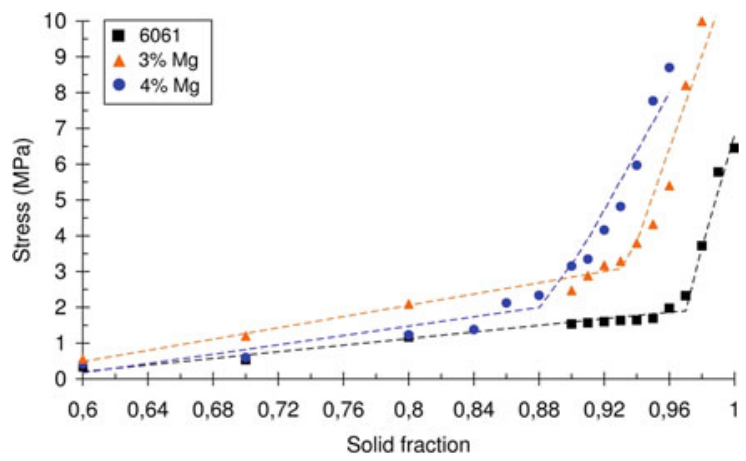

(b)

It should be noted that the stress level developed during solidification depends on the composition of the alloy. When the Si content increases, smaller stresses are developed compared to the 6061 alloy. An inverse trend is observed when the $\mathrm{Mg}$ content increases.

\section{X-Ray Microtomography Observations}

Figure 4 shows 3-D images obtained by X-ray microtomography of the molten zone of some specimens after solidification. The open cracks are in yellow and the thermal gradient is in the vertical direction.

The crack distribution is not homogeneous along the molten zone but the cracks are concentrated in the center. Since the cooling of the sample is due to water flow on both sides of the solidifying zone, the solidification front moves from the edge of the molten zone to the center of the sample. Thus, the central part of the specimen remains the hot point during the cooling step so that this zone experienced the larger strain.

The figure shows also that the $\mathrm{Si}$ and $\mathrm{Mg}$ contents significantly influenced the number of cracks: a significant decrease compared to the 6061 alloy is indeed observed for $\mathrm{Si}$ and $\mathrm{Mg}$ contents equal to 5 and $3 \mathrm{wt} \%$, respectively. 


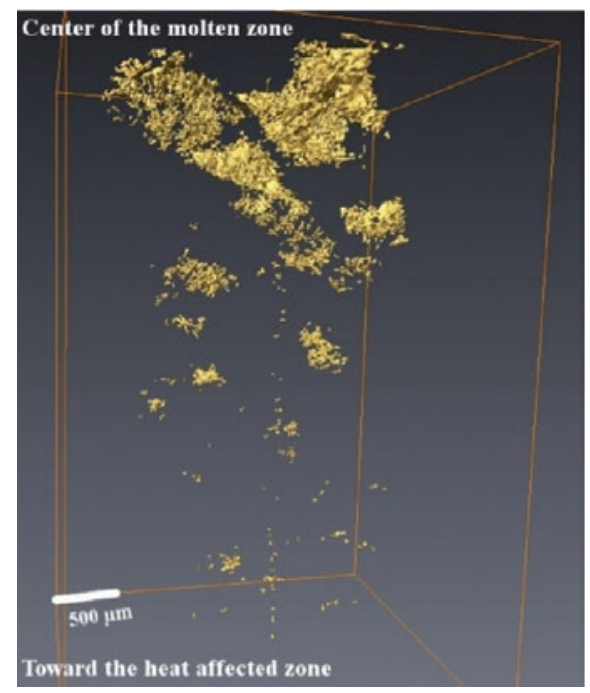

(a)

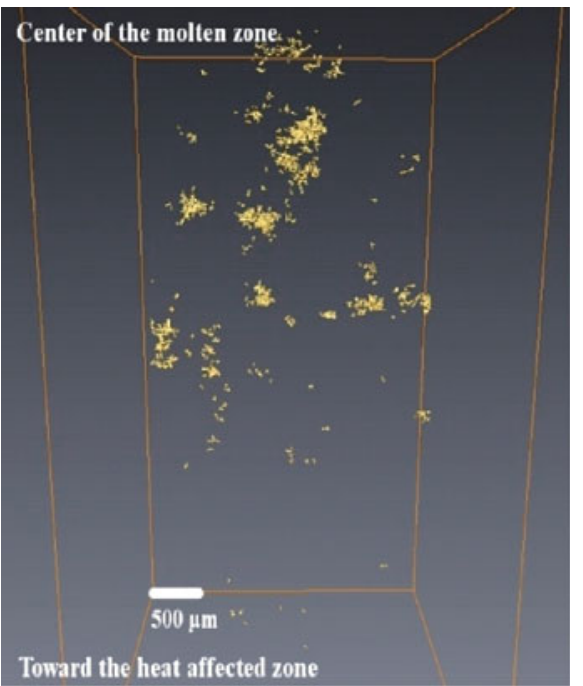

(b)

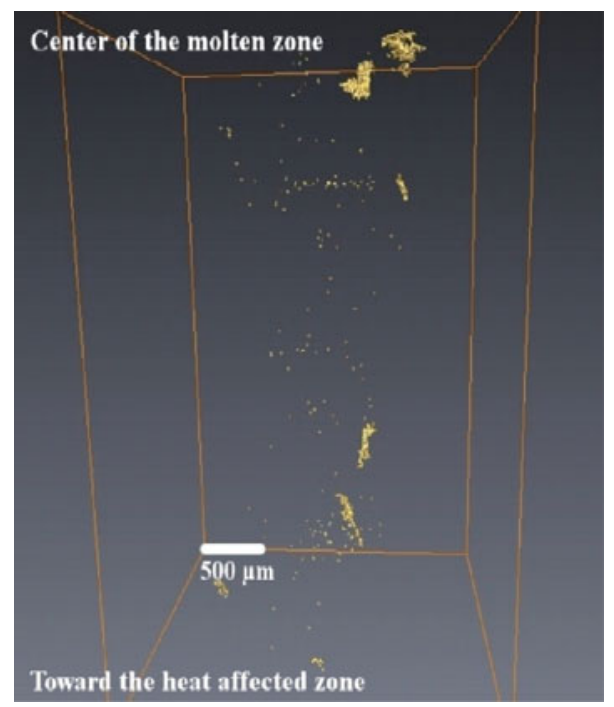

(c)

Fig. 4 3-D images of the molten zone after X-ray microtomography observations performed on: 6061 alloy (a), alloy with 3 wt\% of $\mathrm{Mg}(\mathbf{b})$, and alloy with $5 \mathrm{wt} \%$ of Si (c)

\section{Discussion}

The agreement between solidification conditions occurring in the mechanical test and those encountered during welding will be discussed first. Then the behavior of the 6061 alloy during constrained solidification in comparison with alloys 
containing various $\mathrm{Si}$ or $\mathrm{Mg}$ contents will be discussed. Finally, the sensitivity to hot cracking will be evaluated and compared to the literature.

\section{Comparison Between Conditions Encountered During Constrained Solidification And Welding}

The tests are very close to the solidification conditions encountered during welding for three main reasons. Firstly, constrained solidification is encountered during welding owing to the clamping which is usually applied to the parts to be joined [10]. Secondly, a cooling rate of $80 \mathrm{~K} / \mathrm{s}$ is reached during the solidification of the samples which is of the same order of magnitude as in welding. Thirdly, the microstructure along the sample (Fig. 5) which results from the tests is similar to that found in a welded joint [11]. The molten zone with equiaxed dendrites is observed in the center and more columnar dendrites are found when getting closer to the heat affected zone. The heat affected zone on both sides of the molten zone exhibits a granular structure and a liquation phenomenon (indicated by arrows on the figure).

However, the phenomenon of liquid backfilling encountered in welding is not present here. Therefore the solidification conditions are more severe than in welding.

\section{Behavior of the Alloys Under Constrained Solidification}

The variation of the stress observed when the solid fraction increases is linked to the microstructure changes of the molten zone during solidification. This evolution has been detailed in numerous studies concerning the behavior of semi-solid alloys under tensile strains [3,11-14]. At the beginning of solidification, dendrites are free to move into the liquid. Deformations are accommodated by liquid flow which is easy or by rearrangement of grains. Then dendrites begin to come into contact: the liquid surrounds the dendrites and can circulate between the dendrite arms to accommodate the deformations. This transition is called coherency. In the last stages of solidification, the solid skeleton becomes more and more dense hindering

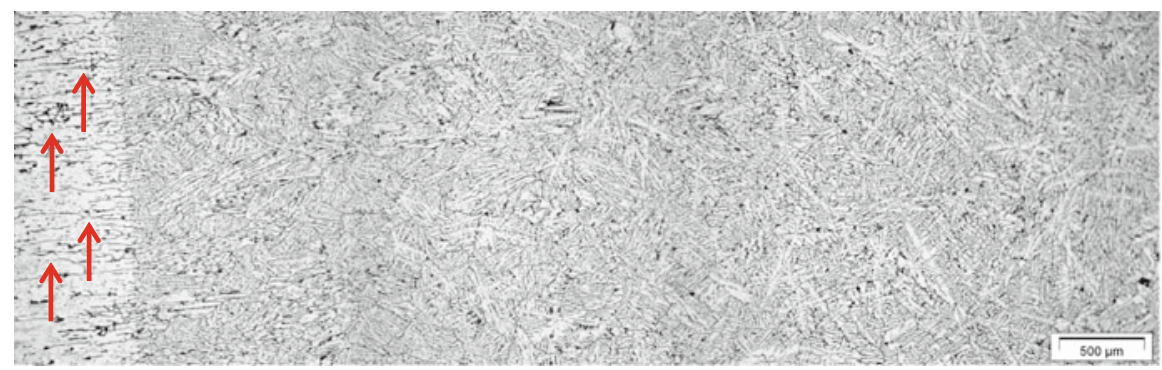

Fig. 5 Microstructure of a 6061 sample tested under constrained solidification (with the heat affect zone on the left and the center of the molten zone on the right) - Keller etching 
the liquid flow which always surrounds the dendrites but in the form of thin films. Finally, at the end of solidification, the surface area of solid-solid contacts increases rapidly and liquid is in the form of isolated pockets. This transition is called coalescence. Consequently, during solidification, two important transitions are present in the microstructure of the semi-solid state: the coherency and the coalescence transition. It is obvious that these microstructural changes will have an impact on the mechanical properties as observed in the curves of Fig. 3.

The solid fraction at which the stress starts increasing underlines the coherency solid fraction which is close to 0.6 whatever the composition of the alloy. The transition for which a change in slope is noticed is due to the coalescence: an important increase of solid-solid contacts results in a faster increase of the resistance of the semi-solid state. The coalescence solid fraction is independent of Si content but depends on Mg content. It is shifted toward lower solid fractions when Mg content increases; which means that the solid skeleton develops earlier in the Mg-rich alloys.

Moreover, $\mathrm{Si}$ and $\mathrm{Mg}$ contents have also an impact on the stress level developed during solidification. For high Si contents, the lower level can be linked to the presence of lower thermal contraction and solidification shrinkage compared to the 6061 alloy. For high $\mathrm{Mg}$ contents, the higher level is the result of the combined effect of a smaller coalescence solid fraction and of lower temperatures compared with the 6061 alloy.

In terms of hot cracking, it seems consequently more interesting to modify the $\mathrm{Mg}$ content. During their solidification, the aluminum alloys exhibit a transition in their failure mode: ductile/brittle/ductile [3, 11, 14, 15]. Thus a solid fraction range exists for which the behavior of the semi-solid state is brittle and sensitive to hot cracking. In general, it corresponds to solid fractions ranging between 0.90 and 0.97. By increasing the Mg content, it is therefore possible to form more solid bridges which hinder crack propagation in this critical solid fraction range.

\section{Sensitivity to Hot Cracking of the Various Alloys}

X-ray microtomography observations have shown that cracks are present in the molten zone (Fig. 4). However, it is necessary to know whether these cracks formed in the semi-solid state or after solidification has been completed. To answer this question, tensile tests have been performed at room temperature on samples previously tested under constrained solidification. The samples have failed in their central part and the fracture surface, shown in Fig. 6, exhibits ductile deformation zones (Fig. 6a) and smooth dendritic zones (Fig. 6b). The presence of smooth dendritic zones suggests that pores and/or cracks are present before the tensile test. Since the as-received alloy does not contain any pores or cracks, it can be concluded that these defects were formed in the semi-solid state during the constrained solidification experiment. Hot cracking has thus occurred during solidification by failure of the liquid films $[11,16]$ and the cracks observed in the 3 -D images are due to this phenomenon. 
Fig. 6 Fracture surfaces obtained after a tensile test at room temperature on the 6061 alloy previously tested under constrained solidification

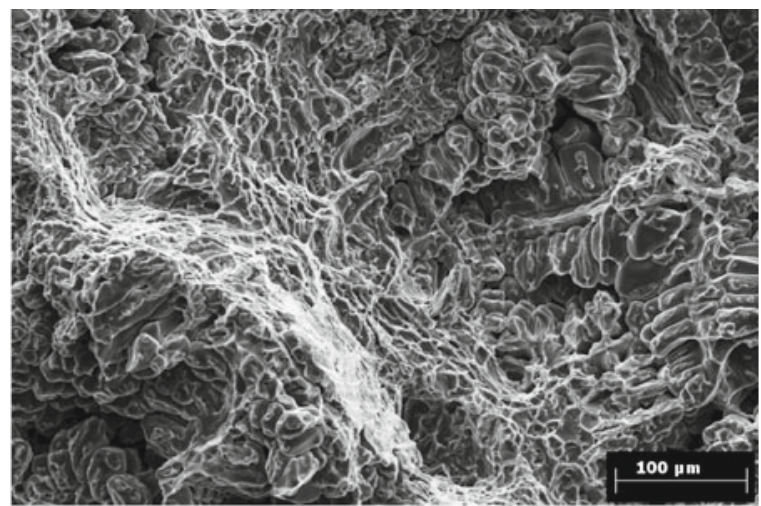

(a)

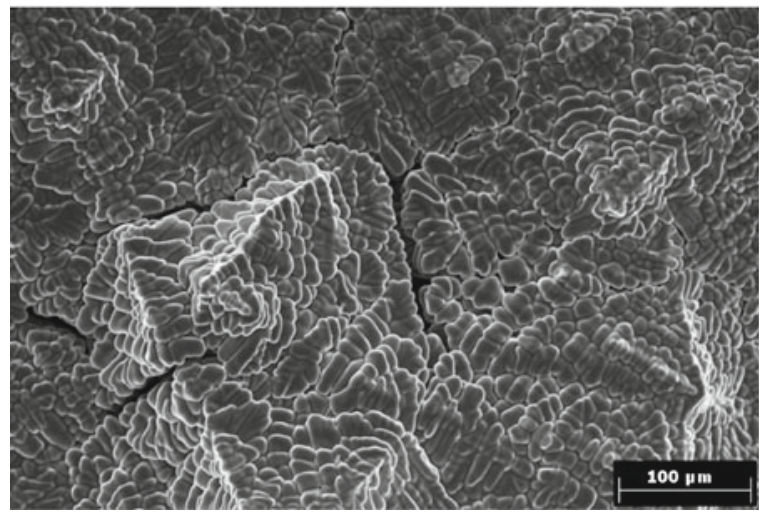

(b)

From the 3-D images obtained by X-Ray tomography, the sensitivity to hot tearing can be determined as a function of the $\mathrm{Si}$ or $\mathrm{Mg}$ contents. Two parameters have been defined: the volume percent of open cracks (Fig. 7a) and the number of cracks per unit volume (Fig. 7b). For both parameters, a standard lambda curve is found as a function of the $\mathrm{Si}$ or $\mathrm{Mg}$ contents with a peak susceptibility occurring for $\mathrm{Si}$ or $\mathrm{Mg}$ contents in the range between 1 and $2 \mathrm{wt} \%$. The alloys become less sensitive to hot tearing than the 6061 alloy when the Si or Mg content exceeds 3 or 2 wt\% respectively. The minimum sensitivity is reached for $5 \mathrm{wt} \% \mathrm{Si}$ or $3 \mathrm{wt} \% \mathrm{Mg}$. However, the susceptibility of the alloy containing $4 \mathrm{wt} \% \mathrm{Mg}$ remains unclear: it seems to be more sensitive than the alloy with $3 \mathrm{wt} \%$. This tendency is more important on the number of cracks per unit volume than on the volume percent of open cracks which suggest the presence of very small pores and/or cracks. This result can be attributed to the threshold procedure and perhaps to the presence of small defects in the initial alloy. It could be also possible that an increase of the $\mathrm{Mg}$ content beyond $3 \mathrm{wt} \%$ increases the hot tearing tendency. Shimizu [17] has studied the hot tearing susceptibility during electron beam welding of 6061 alloy with 4043, 4047 and 5356 alloys used as 
Fig. 7 Hot cracking sensitivity based on the volume percent of open cracks (a) or the number of cracks per unit volume (b)

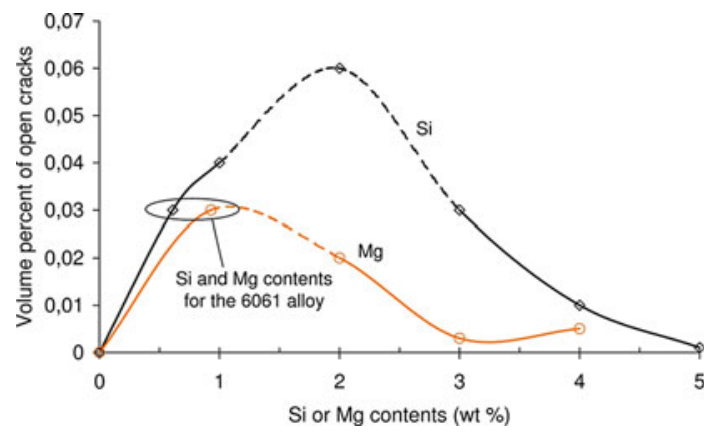

(a)

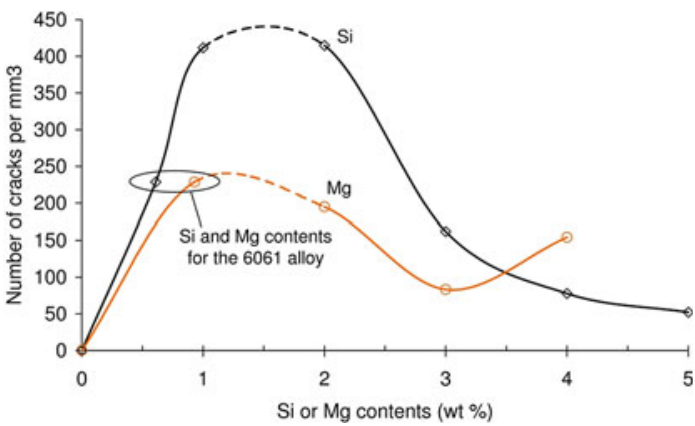

(b)

filler wire. In his study, cracks were found to disappear when the Si content exceeds $3.2 \mathrm{wt} \%$ or the $\mathrm{Mg}$ content exceeds $2.3 \mathrm{wt} \%$. For the behavior of alloys containing different $\mathrm{Mg}$ contents, the minimum sensitivity found by Shimizu is in agreement with our study. However, this is not the case when considering alloys with various $\mathrm{Si}$ contents. It can be assumed that this difference is due to the absence of liquid feeding during constrained solidification in contrast with the welding process.

Moreover, it can be noticed that the alloys containing various $\mathrm{Mg}$ contents exhibit a lower susceptibility to hot tearing than those containing various Si contents. This result is in agreement with the conclusion concerning the effect of $\mathrm{Mg}$ on the strength of the alloy. Increasing Mg content indeed allows obtaining a more resistant microstructure (Fig. 3). This higher resistance is due to the fact that coalescence occurs at a lower solid fraction and that the corresponding temperature ise much lower than that for the base alloy (Table 2).

\section{Conclusions}

1. The tensile test used in this study allows reproducing the conditions encountered during welding in terms of microstructure (equiaxed dendritic molten zone 
and liquation phenomenon in the granular heat affected zone) and solidification (i.e. constrained solidification at high cooling rate). The test allows also measuring in real time the strength of the material as a function of solid fraction.

2. The various alloys prepared by mixing the base 6061 alloy with Si-or Mg rich alloys exhibit the same behavior during solidification. Coherency occurs at a solid fraction of 0.6 and coalescence is observed at a solid fraction of 0.97 whatever the $\mathrm{Si}$ content and at lower solid fractions when the $\mathrm{Mg}$ content increases.

3. X-ray microtomography observations of the molten zone allow quantifying the sensitivity to hot cracking of the various alloys. A lambda curve is found with a peak susceptibility occurring for $\mathrm{Si}$ or $\mathrm{Mg}$ contents in the range from 1 to $2 \mathrm{wt} \%$ and a minimum susceptibility at $5 \mathrm{wt} \% \mathrm{Si}$ or $3 \mathrm{wt} \% \mathrm{Mg}$.

4. The use of a filler alloy from the Al-Mg series seems to be the most appropriate solution to reduce hot cracking during welding of the 6061 alloy owing to the lower susceptibility to hot cracking of alloys containing $\mathrm{Mg}$ compared to those containing Si. Indeed, during constrained solidification of $\mathrm{Mg}$-rich alloys, it was observed that the coalescence of the solid skeleton occurs at lower solid fraction compared to Si-rich alloys. The alloy shows then a higher resistance to crack propagation in the critical solid fraction range.

Acknowledgements One of the authors (EG) is grateful to CNRS (French National Center for Scientific Research) and AREVA for financial support through a scholarship. The authors thank Cédric Gasquères, ALCAN CRV, for providing the ProPhase calculations and Luc Salvo, SIMaP, for his assistance during the processing of the microtomography data.

\section{References}

1. Anderson T (2005) How to avoid cracking in aluminum alloys. Welding Journal:25-27.

2. Cicala E, Duffet G, Andrzejewski H, Grevey D and Ignat S (2005) Hot cracking in Al-Mg-Si alloy laser welding - operating parameters and their effects. Materials Science \& Engineering 395A:1-9.

3. Eskin DG, Suyitno and Katgerman L (2004) Mechanical properties in the semi solid state and hot tearing of aluminium alloys. Progress in Materials Science 49:629-711.

4. Drezet JM (1999) Validation of a new hot tearing criterion using the ring mould test. Journal of Physics IV France 9:53-62.

5. Cross CE, Olson DL, Liu S (2003) Aluminum welding. In: Totten, GE, MacKenzie, DS (Eds) Handbook of aluminium, Vol. 1. Marcel Dekker, Inc, pp. 481-532.

6. Langlais J and Gruzleski JE (2000) A novel approach to assessing the hot tearing susceptibility of aluminium alloys. Materials Science Forum 331-337:167-172.

7. Nagaumi H, Takateru U (2003) Study of the crack sensitivity of $6 x x x$ and $7 x x x$ aluminium alloys. Materials Science Forum 426-432:465-470.

8. Fabregue D, Deschamps A, Suéry M and Drezet JM (2006) Non-isothermal tensile test during solidification of Al-Mg-Si-Cu alloys: Mechanical properties in relation to the phenomenon of hot tearing. Acta Materialia 54:5209-5220.

9. Sigli C, Dif R, Commet B and Warner T (2003) Computer-aided optimization of aluminium alloys for airframe application. Materials Science Forum 426-432:351-356.

10. Cross CE, Boellinghaus $\mathrm{T}$ (2006) The effect of restraint on weld solidification cracking in aluminium. Welding World 50:50-54. 
11. Fabregue D (2004) Phd Thesis, INPG, France.

12. Rappaz M, Drezet JM and Gremaud M (1999) A new hot tearing criterion. Metallurgical and Materials Transactions 30A:449-455.

13. Dahle AK and Arnberg L (1996) The rheological properties of solidifying aluminium foundry alloys. JOM 48:34-37.

14. Giraud E, Suéry M and Coret M (2010) Mechanical behaviour of AA6061 aluminum in the semi solid state obtained by partial melting and partial solidification. Metallurgical and Materials Transactions 41A:2257-2268.

15. Magnin B, Maenner L, Katgerman L and Engler S (1996) Ductility and rheology of an $\mathrm{Al}-4.5 \% \mathrm{Cu}$ alloy from room temperature to coherency temperature. Materials Science Forum 217-222:1209-1214.

16. Lin S, Aliravci C and Pekguleryuz MO (2007) Hot tear susceptibility of aluminium wrought alloys and the effect of grain refining. Metallurgical and Materials Transactions 38A:10561068.

17. Shimizu S (2002) Study on crack prevention in electron beam welding of 6061 aluminum alloy. Journal of Light Metal Welding and Construction 40:23-30. 